HAROLD SHIPMAN: THE AFTERMATH

\title{
Implications of Harold Shipman for general practice
}

R Baker

Postgrad Med J 2004;80:303-306. doi: 10.1136/pgmj.2003.013110

Harold Shipman was an English general practitioner who murdered at least 215 of his patients between 1974 and 1998. A public inquiry is underway, but general practitioners and all doctors also need to consider the implications for their profession. The aim of this paper is to stimulate debate. Issues identified as important to consider include: trust between doctors; attitudes towards failing systems such as cremation certification; acceptance of the duty of accountability; ensuring patients can have reasonable confidence in their doctors; commitment to preventing such a case occurring again; and relationships with patients. It is argued that restricting debate to methods to detect doctors who murder would limit the opportunity to improve medical practice and would constitute a failure to fulfil the duty owed by doctors to Shipman's victims and their families.

Correspondence to: Professor Richard Baker, Department of Health Sciences, University of Leicester, Leicester General Hospital, Gwendolen Road, Leicester LE5 4PW, UK; rb14@le.ac.uk

Submitted 28 July 2003 Accepted

9 September 2003
$\mathrm{T}$ he British general practitioner Harold Shipman was convicted in January 2000 of the murder of 15 of his patients, and of forging the will of one. Although initial concerns had been raised in March 1998 by a local general practitioner (by which time, according to the public inquiry into the case, he had unlawfully killed more than 200 patients $^{1}$ ), he was not arrested until September 1998 because suspicions were raised that he had forged a will. At regular intervals since then, new headlines have appeared in newspapers, or new reports have been issued by the continuing public inquiry into the case, and to general practitioners it must feel they will always be reminded of the dreadful acts of one of their number, and always be held in some way responsible.

An adequate debate among general practitioners about the implications of Shipman for general practice is only just beginning, prompted by the recent reports of the Inquiry. Other than the initial reactions, and some discussions in the governing bodies of the Royal College of General Practitioners and the General Practice Committee of the British Medical Association, there had been little or no debate involving the broad membership of the profession. That needs to change. General practitioners must ask the question: what was it about general practice that enabled a general practitioner to kill more than 200 patients before the alarm was raised?

The aim of this paper is to contribute to the debate in response to this question. First, the initial thoughts of general practitioners about the implications will be discussed. Second, the actions taken so far by government will be summarised. Third, the broader issues confronting general practitioners will be outlined. These are essentially personal reflections based on my own investigation of Shipman's general practice career. $^{2}$

\section{REACTIONS IN GENERAL PRACTICE}

How should general practitioners respond to the initial discovery that a fellow practitioner had used his professional position to murder 15 of his patients, and the subsequent discovery that he killed between 215 and 260 ? One response was to emphasise that Shipman was a murderer who

\section{The editor writes:}

Medicine and nursing have long been concerned with the care and treatment of the sick. Integral to such an approach has been the need to "do the patient no harm". It is for these reasons that, for the last century, patients have readily given their care into the hands of the "caring professions." However, during the last decade we have seen the destruction of the public image of selfless service. The abuse of children has thrown a long shadow over the child caring professions and the murder of patients has seriously damaged both the nursing and medical professions. We can no longer live in a society where trust is linked with an occupation.

Considerable thought went into the decision to devote several pages of this issue to the Harold Shipman Inquiry and its consequences. It is unlikely that we will ever understand his motivations. It is naive to believe that we can guarantee that such a tragedy will never happen again. However, as a profession we need to ensure that there is an effective method of monitoring clinicians and their practices. We need to recognise that deviant and criminal behaviour can occur in any sector of society and that medicine and nursing are no exceptions.

The purpose of inviting a range of senior clinicians to comment on Shipman and his consequences is to further stimulate the debate about how medicine and nursing should be policed and to encourage an open and innovative approach. We have asked these clinicians to comment from a personal standpoint and we would also like to encourage your views. Please visit the full text of these articles on PMJ Online to submit a rapid response (www.postgradmedj.com). - John Mayberry 
was coincidentally also a general practitioner. ${ }^{3}$ Of course this is true, but it does not explain whether, and if so why, the environment of general practice allowed him to murder so many people without detection.

Another response has been anger directed towards the Department of Health or government, ${ }^{4}$ in the belief that they have taken advantage of public concerns following Shipman's conviction to introduce tough controls over general practice.

Some have perceived an attack directed specifically at single handed practices. While there may be a tendency among some managers and policymakers to regard single handed practice as undesirable (quite why in a health service that is meant to be designing services around the needs and preferences of patients is a mystery since patients generally prefer them to large practices), the use of Shipman as a reason for encouraging the end of single handed practice cannot be justified. Since he managed to kill approximately 80 patients while working in two different large group practices, it would be more appropriate to regard Shipman as a general failure of monitoring rather than a failure particular to single handed practice.

Another response has been fatalism, it being argued that steps taken to reduce the risk of murder by doctors are bound to be of limited effectiveness; the determined murderer, it is believed, will always find a way to evade whatever procedures are put in place. ${ }^{5}$

It is difficult when confronted with these reactions not to be reminded of the features of the bereavement reactionguilt, anger, and depression. Perhaps for many general practitioners that is in some respects what it has been, an experience of bereavement following what must have seemed like the death of the image of the general practitioner as sometimes fallible but almost always virtuous and humane.

\section{CHANGES NOW UNDERWAY}

The Secretary of State for Health announced several changes the day after Shipman's conviction (box 1). The Fundamental Review of death certification and investigation ${ }^{6}$ has made recommendations for the reform of the coronial service and death certification procedures. In its second report, the Inquiry, chaired by Dame Janet Smith, has also made recommendations about death investigation and certification. ${ }^{7}$ There are similarities between the recommendations of the Review and the Inquiry, and both support the investigation of deaths due to medical error or negligence by the coronial service. If this recommendation is implemented, in future families will be more able to report concerns about medical care to coroners. While some doctors may be anxious about this proposal, it is surely right that coroners should be able to give families an accurate judgment on the cause of death of the deceased.

A long list of issues is still to be considered by the Inquiry (box 2). While the outcome is impossible to anticipate, it is obvious that the impact on general practice could be enormous.

\section{IMPLICATIONS}

Three general points should be made first.

\section{Patient trust}

First, it is important to note that general practice still has the trust of patients. Although a loss of trust might have been anticipated, this has not happened. Individual patients still trust their personal doctors, there has not been a flood of accusations of murder against other general practitioners, a steep increase in complaints or litigation, and surveys continue to indicate that the public trusts their doctors. Patients have adopted a sensible approach, and this is a
Box 1: Actions and recommendations following Shipman's conviction

Announced by Secretary of State for Health, February 2000

- An inquiry into the issues raised by Shipman's murders.

- Requirement for doctors to disclose criminal convictions or action by professional regulatory bodies before appointment to medical lists.

- General practitioners to report deaths in their surgeries and other serious incidents to health authorities.

- A clinical audit of Shipman's past clinical practice.

Recommendations of the clinical audit ${ }^{2}$

- A review of systems to monitor general practitioners.

- Monitoring of mortality of patients of general practitioners.

- Revision of certification system.

- Assessment of general practitioners' records in revalidation.

- Review of policy on retention of records of deceased patients.

- Inspection of general practitioners' controlled drugs registers.

Fundamental review of coronial service ${ }^{6}$

- Sixty coronial districts in England and Wales.

- One statutory medical assessor per district to oversee certification, investigate natural deaths, and link with public health.

- Two tier certification for all deaths.

- Lack of care, unresolved concern-refer to coroner (including by families).

- Periodic audits of certification.

Inquiry's Third Report ${ }^{7}$

- Radical reform of the coronial service.

- Medical coroners to work with judicial coroners.

- Revised death certificates to be completed for all deaths.

- General Medical Council to impose on doctors a duty to cooperate with certification system.

- Random and targeted checks of certificates.

- Deaths possibly due to medical error or negligence to be investigated by coronial service.

lesson in itself. We should trust them to appreciate the potential risks of over-reaction, and should not be afraid of discussing with them or their representatives the changes that should be made in response to Shipman. ${ }^{8}$

\section{Prevent murder or more general lessons}

Second, should the debate after Shipman be confined to ways to prevent murder by general practitioners, or should it consider wider lessons about improving general practice? The Inquiry has not restricted itself to a narrow perspective, and neither should general practitioners-if the murder of 230 or so patients by a general practitioner is not sufficient cause for taking a long, hard look at general practice, what is?

The systems to monitor general practitioners did not just fail to detect these murders, but they also failed to detect poor record keeping, fabricated entries in records and cremation 
Box 2: Issues still to be considered by the Inquiry

- Controlled drugs.

- Reporting of concerns by professionals.

- Monitoring mortality rates.

- NHS and General Medical Council disciplinary procedures.

- Recording information about past history of general practitioners.

- Monitoring performance (prescribing, records, complaints, role of practice staff).

- Accountability of general practitioners and health authorities.

and death certificates, misappropriation of diamorphine, failure to keep a controlled drugs register, and repeated lying to relatives and health professionals. The Inquiry has already found that the medical profession has condoned low standards in the completion of Form C of cremation certificates. $^{79}$ Consequently, the response to the Shipman case cannot be confined to review of measures to detect murder.

\section{Trust between general practitioners}

Third, should general practitioners no longer trust each other? The general practitioners who completed part $\mathrm{C}$ of the cremation forms of Shipman's patients assumed that the occasionally curious stories, or repetition of unusual occurrences such as death with Shipman present, were in fact readily explained natural events. They trusted Shipman, and accepted his accounts of what had happened. It might now be concluded that general practitioners should no longer be so trusting of each other, and that a professional relationship based on trust should be replaced by one of doubt and suspicion. This would be a sad development. Although it is a professional responsibility to seek adequate information when the circumstances of death appear strange, a general attitude of mistrust would be destructive.

Now five specific points will be discussed bearing on the attitudes and behaviours of professionals, general practitioners in particular.

\section{Get angry and take action}

Anger is a natural reaction to the murder of patients by a doctor, but anger is not enough. Action to remedy the contributory weaknesses in health care is mandatory. Perhaps more anger among doctors about the essentially worthless system of cremation certification or the neglected procedures for monitoring controlled drugs would have led to changes that would have made the murder of patients more difficult. Why did doctors tolerate these systems?

It is possible to become so familiar with the failings of old, established systems that we forget to notice them. The derelict systems that result were originally devised to protect patients but end up as dangers to their safety, and Shipman was successful in exploiting their weaknesses. We should not forget to notice the failings of poor systems, nor should we rely on individuals to notice problems and report them. Health care organisations must actively encourage the reporting of problems by showing that they act on the reports that reach them.

If making change is difficult and the obstacles seem insurmountable, an attitude of helplessness takes over. After successive waves of imposed reforms, general practitioners have come to believe there is little they can do to change things. The fragmented nature of national and local professional leadership has not always been successful in influencing reform or in helping doctors to respond positively, and may have conveyed to doctors that they belong to a relatively powerless profession.

\section{Accept the duty of accountability}

Shipman was regarded by many as a good doctor. He may have been an occasionally difficult character, but it was believed that he was committed to his patients and was competent. Yet when investigating his clinical practice after the trial, I was struck by the lack of objective evidence about his competence. Despite his history of drug misuse and a number of patient complaints made against him, there appeared to have been no past systematic process in which he had been objectively assessed, and it was impossible to come to any conclusion about his competence. This is impossible to defend. How can a patient be expected to consult a doctor with confidence when the profession cannot offer objective confirmation of the doctor's competence? The failure of systems to monitor general practitioners to detect unacceptable aspects of care have been mentioned above, and these failures remained undetected even when complaints had been made about Shipman. ${ }^{2}$ Since the failures were so extensive, it is not appropriate, nor would it be worthy of the medical profession, to limit debate to methods for detecting murder. The failures have raised a question about the profession's commitment to ensuring that patients can have reasonable confidence in their doctors, and it is fundamental to the future of the relationship between doctors and patients in the UK that this question receives an adequate answer.

Revalidation is not primarily intended to detect doctors who murder, but if undertaken with sufficient rigour should provide evidence about fitness to practise. ${ }^{10}$ When revalidation is introduced, it should be possible to reassure patients about their doctor's competence with greater conviction (although doubts about the adequacy of relying on appraisals to provide most of the information about the doctor remain to be answered) but why did doctors resist regular reassessment of competence for so long? We have been wrong for assuming the right to practise without also accepting the responsibility to demonstrate continued competence. The reasons for the error can be disputed but the conclusion must be clear-we did fail to fulfil the duty of accountability.

Revalidation is coming-eventually-but it is not enough. Professionals should aspire to more than minimal competence, and local networks are needed to encourage general practitioners to test themselves against higher standards. The Royal College of General Practitioners has developed relevant methods, yet Shipman was not a member of the College, and since he was also not a trainer, he would have avoided peer assessment of his performance. Strong local structures are needed to draw every practitioner into a community of peers to provide both practical support and a continuing challenge to maintain or improve performance.

\section{Monitor what is truly important}

Even though information about numerous aspects of care are collected routinely, the mortality rates of patients of general practices or general practitioners are not, and Shipman was able to murder over a 20 year period undetected until he decided to forge a will. It is essential to monitor the most important aspects of practice, and the survival of patients is unquestionably the most important. Without such monitoring, it is impossible to discover when things go wrong-until it is too late. Monitoring mortality in general practice will require the development of appropriate techniques, ${ }^{11}{ }^{12}$ but this should not be an excuse for inaction. While a monitoring system cannot be guaranteed to identify small excesses of mortality, in Shipman's case the excess would have been 
detected well before the eventual total of over 200 was reached.

\section{Never again}

Serial killing by a doctor must be extremely rare. When it happens again, the perpetrator is bound to try to avoid detection by whatever monitoring systems are then in place, and since it is impossible to predict the pattern that will be followed by the next serial killer, the construction of a process to detect that killer is difficult. It may be thought, therefore, that only limited effort should be devoted to the revision of death certification procedures and the introduction of a monitoring system. But although it is true that the detection of a small number of killings by a doctor would be difficult, a case such as Shipman's can never be allowed to happen again. Doctors would not deserve public trust if they remain unable to identify a doctor who murders hundreds of patients. While the difficulties have to be recognised, everything possible must be done to make sure Shipman remains unique. Fatalism on this issue would be a betrayal of patient trust.

\section{The doctor-patient relationship}

The relationship observed by John Berger between John Sassall and his patients has served as an image of ideal general practice for generations of general practitioners. ${ }^{13}$ In this relationship, the doctor is a member of a community, having lived among and shared the lives of a group of people over several years. They have come to understand each other. The patients have learnt that when they need help, the doctor will be there, and most of the time his advice will be sound. They respect his judgment, and they respect him.

It wasn't very different in Shipman's practice. He was respected by his patients, and his advice was regarded as sound. He was always there when he was needed, and often seemed sensitive to his patients' problems. He lived among his patients and shared their joys and tragedies. Many described him as an old fashioned doctor, and an element of paternalism does appear to have been part of his style.

It would be wrong to claim that paternalism is still the predominant form of general practitioner-patient relationship. Patient involvement, patient partnership, and the expert patient are but a few of the ideas and initiatives that have sought to put patients and doctors on a more equal footing. However, Shipman appears to have taken care to create a relationship of paternalism in order to protect himself from detection. He took the old, idealised image of the doctorpatient relationship, and deliberately distorted it to enable him to conceal murder. The ease with which he did this is frightening, and is a powerful reason for rethinking the future of the doctor-patient relationship. If he could distort the relationship, other doctors could also manipulate it for self serving reasons, for example to control decision making, conceal errors, or even worse.

Methods are needed for making it more difficult for doctors to manipulate relationships with patients. Openness will be a key element. This could include sharing records with patients, copying referral letters to them, and the provision of increasingly detailed information about illness and treatments. Information about the doctor's performance should also be available, and might include summaries from audits and reports of objective assessments of clinical competence. Of course, most patients would pay little attention to this information, but the principle of openness would ensure that they could check their doctor's advice or performance if they should wish.

\section{CONCLUSIONS}

General practitioners cannot be held responsible for the actions of Harold Shipman. They are, however, responsible for learning from what happened and making changes where they are needed. They must provide an answer to the question: what was it about general practice that enabled a general practitioner to kill more than 200 patients before the alarm was raised? This paper is intended as a contribution to a debate in response to this question. While some general practitioners will disagree with the points made, I hope they will take part in a discussion about the implications for general practice.

There are practical changes that can be made to monitoring systems such as death and cremation certification, and review of controlled drugs handling. But there are also important general issues that general practitioners and all doctors need to face, such as whether we are serious about revalidation as a procedure to ensure that patients can have reasonable confidence in their doctors, how we can develop an attitude of intolerance towards failing systems, and how we can promote relationships with patients that make manipulation by the occasional devious doctor impossible. Shipman's murders have placed a duty on today's generation of general practitioners to learn every relevant lesson from what happened and to respond accordingly. A debate about the potential lessons is the first step towards fulfilment of that duty.

\section{ACKNOWLEDGEMENTS}

This paper is based on the 45th annual Gale memorial lecture, delivered in Stonehouse, Gloucestershire in June 2003.

\section{REFERENCES}

1 Dame Janet Smith, chairman. The Shipman inquiry. First report. Volume one. Death disguised. Manchester: The Shipman Inquiry, 2002.

2 Baker R. Harold Shipman's clinical practice, 1974-1998. London: Stationery Office, 2001.

3 Wyndham R. Second opinion. BMA News Review 2000 March:35

4 Bogle I. Doctors must not be driven out of practice. BMA News Review 2001 February: 25.

5 O'Neill B. Doctor as murderer. BMJ 2000;320:329-30.

6 The Report of a Fundamental Review 2003. Death certification and investigation in England, Wales and Northern Ireland. Cm 5831. London: Stationery Office, 2003

7 Dame Janet Smith, chairman. The Shipman inquiry. Third report. Death and cremation certification and the investigation of deaths by coroners. Manchester: Command paper Cm 5854, The Shipman Inquiry, 2003

8 Baker R. The Shipman case: the individual. P 25-35. In: Harrison J, Innes R, van Zwanenberg T, eds. Rebuilding trust in healthcare. Abingdon: Radcliffe Medical Press, 2003.

9 Horner JS, Horner JW. Do doctors read forms? A one-year audit of medical certificates submitted to a crematorium. J R Soc Med 1998;91:371-6.

10 McKinley R, Fraser RC, Baker R. Suggested model for directly assessing and enhancing clinical competence and performance in clinician revalidation. BMJ 2001;322:712-5.

11 Baker R, Jones D, Goldblatt P. Monitoring mortality in primary care after Shipman. BMJ 2003;326:274-6.

12 Aylin P, Best N, Bottle A, et al. Following Shipman: a pilot system for monitoring mortality rates in primary care. Lancet 2003;362:485-91.

13 Berger J. A fortunate man. London: Allen Lane, 1968. 